\title{
NOTAS PARA UM ESTUDO SOBRE A IMIGRAÇÃO NORTE-AMERICANA E SUAS INFLUÊNCIAS NA CULTURA BRASILEIRA (1823-1889)
}

Luiza Kliemann

\section{Fatores motivadores da imigração norte-americana no Brasil}

No momento em que dentro de seu próprio território são apaziguados os ânimos, depois das lutas por posse de terras com a França e a Inglaterra, os Estados Unidos da América vão voltar-se para a fronteira oeste, para o Texas mexicano, para a América Central e, decorrentemente, para a América Latina, onde disputarão com a Inglaterra a supremacia econômica.

Sob a égide da doutrina Monroe, ${ }^{1}$ lançam-se os norte-americanos à América do Sul que, por seu lado, vê na mesma a possibilidade de saneamento dos seus problemas políticos, o reconhecimento de sua independência e da estruturação de suas nações pelas "grandes".

As esperanças dos latino-americanos, no entanto, não chegarão a se concretizar, porque tudọ não passava de uma teoria que visava afastar a Santa Aliança, a Inglaterra ou mesmo qualquer nação da Europa que tivesse interesse nos territórios da América. Quando aqueles se derem conta, os E.U.A. já estarão adiantados na sua expansão imperialista.

Não nos cabe aqui analisar as motivações que levaram os norte-americanos ao Texas, a Cuba, a Nicarágua, mas sim as que os levaram a uma expansão até a América do Sul e, mais precisamente, ao Brasil. Sabemos, no entanto, que esta expansão seguiu uma mesma linha política, um mesmo objetivo econômico e as mesmas características ideológicas da do Norte, acrescentando-se aqui o fato de a América Latina representar, com seus metais, suas terras férteis e seus rios navegáveis, a satisfação dos anseios econômicos tanto dos nortistas industriais como dos sulistas agricultores e escravagistas.

$\mathrm{O}$ interesse pela terra e pelo que a mesma poderia oferecer economicamente vem primeiro; a gente americana vem depois.

Assim sendo, vamos encontrar desde muito cedo nos E.U.A. uma preocupação com a Amazônia brasileira. Arthur Cezar Ferreira Reis, tratando da navegação do Amazonas, nos diz:

Quando se conquistou a independência, o problema do acesso ao interior da Amazônia pelo estrangeiro que desejasse vir instalar-se nela, ou descobri-la para a ciência, ou ainda para o giro mercantil que desse forma a sua vida econômica, criando mercados no exterior à sua produção tão interessante e tão desejada, era um problema de que todos cedo se aperceberam. ${ }^{2}$ 
O Brasil estava atento para a ambição estrangeira, mas encontrava-se sem condiçõts para enfrentar a floresta. As tentativas que haviam sido feitas não passavam de fracassos sobre fracassos, resultando disso que a ocupação da área resumia-se em grupos humanos pobres, que viviam de um comércio ribeirinho, a nível de subsistência.

Por outro lado, a navegação do rio, como simples meio de comunicação ou pela atividade comercial, era feita por embarcações à vela ou remo, não possibilitando o crescimento da região, o alargamento dos limites da floresta, o seu povoamento. ${ }^{3}$

É neste momento, 1826, que entram em cena os E.U.A. Atentos para os problemas da América Latina e para suas riquezas, idealizam um plano objetivo de navegação, exploração e colonização do rio Amazonas, plano este que vem encabeçado por uma companhia denominada "The Amazon Steam Navigation Company," sob a proteção de José Silvestre Rebelo, ${ }^{4}$ representante brasileiro em Washington. O governo do Pará, desconfiado das intenções, não deixa o navio "Amazon" seguir seus objetivos, criando, a partir deste momento, um atrito entre os E.U.A. e o Brasil.

Presidia o Pará, que compreendia a essa altura o que é hoje o Estado do Amazonas, José Félix Pereira de Burgos, que se apressou em convocar uma grande assembléia em palácio, dela participando as autoridades civis, militares e eclesiásticas, comerciantes e pessoas da maior importância da sociedade local para deliberar acerca do comportamento em face da retumbante novidade. Deveria ser concedida a licença impetrada para que o barco subisse o Amazonas? Mesmo sem autorização especial do Rio? Que resultaria para a região das viagens e, embarcação que viria a substituir a ronceira frota local? E que efeitos produziria, na concorrência, sobre aqueles milhares de brasileiros que viviam ligados ao imediatismo da frota ronceira, remando, movendo velas, embarcando a carga que elas transportavam?

A assembléia assustou-se com toda aquela imensa modificação de vida que resultaria, seguramente, da novidade, e decidiu que a paz social e as condições econômicas vigentes não fossem alteradas, recusando a licença. ${ }^{5}$

As investidas norte-americanas aos portos brasileiros desde a sua abertura eram um fato constante; mas isto, na competição comercial, não havia ainda atemorizado ao governo brasileiro, que tomou o caso do "Amazon" como uma penetração territorial. O Império acabou tendo que pagar uma indenização pelos prejuízos causados à companhia norte-americana, uma vez que o tutor de tal empreendimento era um brasileiro. A questão da indenização prolongou-se por muitos anos, mas nem por isso arrefeceram as tentativas norte-americanas de colonizar a região.

Um ponto de capital importância foi a campanha do tenente Mathew Fontaine Maury, que, a partir de 1845 , passa a agitar a imprensa e as camadas econômicas a fim de abrir-lhes os olhos para as riquezas brasileiras. Queria ele que os americanos colonizassem o norte do Brasil transplantando para cá parte de sua população negra. ${ }^{6}$ A propaganda era feita com base nas possibilidades econômicas que a nova terra poderia oferecer e na necessidade do desenvolvimento do campo científico, no qual a região tropical, com sua flora e fauna, tinha lugar preponderante. Para Maury, a navegação do Amazonas era tão importante quanto a construção da estrada de ferro que ligaria o Atlântico ao Pacífico e seu livro "O Amazonas $e$ as Costas Atlânticas da América Meridional" falava nas possibilidades de se constituir uma "República Amazônica," o que veio a mobilizar comerciantes, flibusteiros, liberais, armadores e escravistas para uma imigração em massa. ${ }^{7}$ 


\section{Notas para um estudo...}

Auxiliando os ideais imperialistas de Maury, propagava-se o "Destino Manifesto" e o grupo denominado "Jovem América." O primeiro surge da expressão publicada em 1845 no The Democratic Rewiew, que tomou um sentido romântico e lírico, e que aparecia em todos os arroubos de oratória. Significava, em resumo, que a expansão ilimitada era o destino da nação norte-americana.

0 autor da teoria, John L. Sullivan, teria assim se expressado:

O futuro ilimitado e infinito será a grandeza americana. No seu magnífico domínio do espaço e do tempo, a nação de muitas nações está destinada a manifestar a excelência dos princípios divinos. Terá por assoalho um hemisfério e, por teto, o firmamento constelado de estrelas. 8

Dentro da mesma linha era traçado o programa da "Jovem América," que proclamava a predestinação geográfica da América do Norte e a necessidade do alargamento da área de liberdade do mundo. Este movimento surgiu da ala política democrática e empolgou o país, fazendo com que nos E.U.A. "o nacionalismo e o expansionismo beirassem as raias do delírio." 9

Intensifica-se a expansão para o sul da América, mas a mesma propaganda que faz delirar os norte-americanos, abre,por outro lado,os olhos dos brasileiros que, na pessoa de Sérgio Teixeira de Macedo, representante do Brasil nos E.U.A., vai iniciar a reação expressa em ofício a Paulino José Soares de Souza, Ministro dos Negócios Estrangeiros. O ofício de 14 de novembro de 1849 dizia que:

[. . . ] a franqueza da navegação [o Amazonas] iria abrir a porta à formação de estabelecimentos americanos, a uma grande imigração deles e, por conseguinte, à manobra com que se verificou a usurpação do Texas. ${ }^{10}$

A posição irremovível do Brasil quanto à abertura do Amazonas levou os E.U.A. a fazerem, inclusive, ameaças de uma penetração pela força, o que não intimidou a monarquia, que se protegeu através da concessão da navegação do rio e conseqüente colonização a Irineu Evangelista de Souza, o Visconde de Mauá (1852), com o compromisso de que esta fosse feita por imigrantes oriundos da Europa. ${ }^{11} \mathrm{~A}$ cláusula que se referia aos imigrantes tinha razão de ser, porque várias eram as tentativas de imigração planejada que estavam fazendo os norte-americanos em relação ao Brasil.

Assim, em 1848, Joshua Dodge propôs a emigração de 20.000 pessoas dos E.U.A. para o Pará. Em 1852, James Gasden, político de Washington, pretendeu fixar seus escravos na Amazônia; em 1853, um americano chamado Collins queria naturalizar-se brasileiro e trazer quinhentas pessoas para aquela região. ${ }^{12}$

Com o advento da guerra civil, cessam por algum tempo as investidas sobre a Amazônia, pois as preocupações internas são maiores do que as de política expansionista. Em relação ao Brasil, vamos encontrar somente as discussões entre sulistas e nortistas quanto à quebra de neutralidade por parte do governo imperial ao proteger em suas costas os navios confederados.

Em 1865, no entanto, o Sul é vencido pelo Norte e, a partir de 1866, a política dos E.U.A. força os sulistas à emigração, uma vez que o predomínio ianque se faz cada vez mais atuante. 
O Império via com simpatia os sulistas escravagistas, por estar, naturalmente comungando com o ponto de vista dos mesmos e, também, por ter receios de que abolição da escravidão no norte da América viesse a interferir na vida brasileira de manei a acelerar processo idêntico já em andamento. Este ponto de vista e a necessidade mão-de-obra que se fazia imperiosa como aumento da produção cafeeira, favorecem mudança nas atitudes brasileiras, que serão solidificadas e auxiliadas pela subida de un gabinete liberal ao governo, o qual, numa atitude à primeira vista contraditória, irá abrir navegação do Amazonas, atraindo assim, como havia feito com os europeus, os america nos.

Favorecida a situação por parte dos brasileiros, recrudesce a propaganda para emigração nos E.U.A. e, muitos americanos, na sua maioria sulistas, partirão em direção nova "terra da promissão".

\section{Os imigrantes norte-americanos no Brasil: contribuições culturais}

Como vimos então, depois de pressões e contrapressões, o problema maior para os norte-americanos estava resolvido com a abertura do Amazonas. O fato de o governo brasileiro incentivar a imigração veio tentá-los também a se estabelecerem mais ao sul do Brasil, nas zonas das fazendas de café, nas terras devolutas de São Paulo, Rio de Janeiro, Espírito Santo e Minas Gerais.

A documentação referente a estes imigrantes é escassa e contraditória, mas o que possuímos nos torna possível, mesmo assim, localizá-los geograficamente e estudar sua áreas de influência.

A propaganda nos E.U.A. fazia crer que mais de 50.000 sulistas teriam vindo para ? América do Sul, o que depois foi oficialmente negado, baixando-se o número para 10.000, sendo que destes, 2.000 entraram no Brasil. A distribuição destes imigrantes nos leva a localizá-los em São Paulo, Amazônia, Espírito Santo, Minas Gerais e Rio de Janeiro por ordem numérica de população. ${ }^{13}$

Assim sendo, 800 localizaram-se em São Paulo, ficando distribuídos em trếs colônias: a primeira, a cargo do Rev. Ballard Smith Dunn, em Juquiá, às margens do rio Iguape, quase na fronteira com o Paraná - colônia que recebeu o nome de Lizzieland, en homenagem à filha do colonizador; a segunda, a colônia de Xixirica, no chamado Eldorado paulista, ficou a cargo do Dr. James MacFadden Gaston; a última, a de São Lourenço, a mais distante de todas, a cargo de Mr. McMullen e do C.l Bowen. Duzentos imigrantes situaram-se oficialmente em Santarém, próximo à embocadura do rio Amazo nas, e os restantes espalharam-se pelas províncias do Império, sendo absorvidos quase que imediatamente pelas populações urbanas. ${ }^{14}$

Criaram-se companhias encarregadas da imigração; escreveram-se livros que foratl editados e propagados nos E.U.A.; o governo brasileiro incentivou oferecendo terras ad confederados à base de 22 a 40 cents o acre $(0,405 \mathrm{ha}) ;^{15}$ mas tudo isto de nadl adiantou frente aos problemas que os imigrantes começaram a enfrentar.

Os americanos vindos para o Brasil não eram, como se acreditava a princípio somente fazendeiros a fugir dos nortistas, mas homens das mais variadas procedência 


\section{Notas para um estudo...}

inclusive nortistas, que com a guerra de secessão tinham perdido suas riquezas ou sua chance de adquiri-las e que vinham ao Brasil em busca de melhores dias.

Ao chegarem aqui, depois de certa recepção, os imigrantes eram abandonados à sua sorte numa terra fértil, é verdade, mas assustadora pela sua tropicalidade como era o caso da região de Santarém, ou disputada por outros imigrantes e pelos próprios da terra como no caso da região sul. Não havia sido a tropicalidade um dos grandes obstáculos que os portugueses tiveram que enfrentar quando do povoamento e colonização do Brasil? Não está até hoje aí a floresta virgem do Amazonas a desafiar o homem brasileiro?

A propaganda que se fizera nos E.U.A. também falava da existência no Brasil do regime escravista e de mão-de-obra barata que viria a assegurar o progresso dos agricultores norte-americanos na nova terra. Isto soava como música aos ouvidos dos sulistas que, ao chegar aqui, encontravam um processo de abolição em pleno andamento, uma escassez muito grande de mão-de-obra, então desviada para os cafezais. Quando conseguiam escravos, estes eram inadaptados ao tipo de trabalho para o qual estavam destinados: o plantio e a colheita do algodão. Não era um braço "industrializado" que conhecesse a técnica e os mecanismos para a boa produção algodoeira. As terras, por sua vez,não eram as ideais e o tipo de solo não permitiu na maioria das vezes o uso do arado e outros mecanismos aqui introduzidos e utilizados nos E.U.A. pelos agricultores.

Ao mesmo tempo que se desenvolvia a imigração sulista com fins econômicos mais acentuados, o governo norte-americano forçava uma emigração de evangelistas nortistas que tinham como missão preparar o caminho para a Invasão Evangélica do Brasil, o que na realidade veio a transferir para o nosso território as divergências entre sulistas e nortistas, agravando o problema da adaptação e da assimilação. ${ }^{16}$

Por outro lado, muitos dos que vieram trabalhar a terra acabaram ficando nas zonas urbanas e dedicando-se às profissões liberais, contribuindo assim para uma assimilação mais rápida e para o apagamento dos contornos culturais das colônias primeiramente projetadas.

Praticamente todos os núcleos de imigrantes norte-americanos desapareceram e, por incrível que possa parecer, o que prosperou foi uma pequena cidade paulista, chamada primeiramente Santa Bárbara e depois Vila Americana, local para onde afluíram os imigrantes que sobraram da malograda empresa colonizadora. O núcleo amazonense, segundo o depoimento de um descendente do grupo que veio para Santarém, rapidamente desapareceu. Muitos voltaram para os E.U.A., "outros morreram e outros se dispersaram." 17

Ali, na Vila Americana, ou melhor, a partir dela, é que vamos encontrar alguma influência na área cultural. ${ }^{18}$ Entre as contribuições estará o sistema educacional aos moldes americanos, como por exemplo a estrutura montada pelo conhecido Mackenzie de São Paulo. A introdução de novas sementes na agricultura, principalmente no que se refere à cultura da melancia, proporcionará o aparecimento de novos gostos na alimentação do brasileiro. $\mathrm{O}$ amor à tecnologia, o uso do arado e da máquina de costurar, $\mathrm{O}$ desenvolvimento dos meios de transporte como a carruagem aberta de quatro rodas, o conhecido "trolley" que passou para o costume brasileiro, são outras tantas contribuições: 
Não foi preciso esperar muito tempo para que se estabelecessem entre as cidades e vilas nascentes do centro-oeste paulista linhas de comunicação servidas por semelhantes veículos, verdadeiros precursores, nesse caso, das jardineiras. Sua disseminação como instrumento de locomoção tipicamente rural foi intensa e rápida. E para prova de sua popularidade cumpre dizer que encontrou lugar de honra no próprio cancioneiro caipira:

Sentado num tróio d'oro
Com os assento de prata
Eu irei todo chibante
Ver si prendo aquela ingrata

A melhoria das condições de locomoção proporcionou também o aparecimento de horas de lazer, que pode ser exemplificado pelo costume do piquenique, onde famílias inteiras se agrupavam no campo nos fins de semana, a fim de passar horas ao ar livie, comendo, bebendo, dançando, jogando.

No entanto, é praticamente só isto que podemos arrolar como contribuição a partị dos imigrantes norte-americanos que "não passaram de um capítulo a mais na história da aculturação das inúmeras minorias que escolheram o Brasil como sua pátria adotiva." ${ }^{20}$

Agora, o fato de a imigração não ter sido expressiva não anula as grandes influências culturais norte-americanas que o Brasil sofreu, a partir deste periodo, por outras fontes através da economia, das relações político-diplomáticas, do intercâmbio nas áreas de comunicação e expressão, etc.

Após a Guerra de Secessão, os E.U.A. entravam em fase de franco progresso tecnológico. Na comemoração do centenário de sua independência, por ocasião da exposição de Filadélfia, eram visíveis as invenções de Graham Bell e Thomas Edison, 0 telefone e a luz elétrica, o desenvolvimento da maquinaria agrícola que viria a substituir mão-de-obra, o crescimento da rede ferroviária e a urbanização.

O Brasil, na pessoa de seu próprio monarca, D. Pedro II, logo assimilou os novo inventos, adquirindo-os. O primeiro telefone foi instalado em 1877 pela "Western and Brazilian Telegraph Company," e a concessão para introduzir a luz elétrica no Brasil fo dada em 1879 a Thomas Edison. ${ }^{21}$

Estas inovações foram o primeiro passo para a entrada livre e bem acolhida de tod uma gama de tecnologia e produtos dela decorrentes, que vieram, no período republicano a avassalar a sociedade e a cultura brasileira, muitas vezes em auxílio, mas outras tanta em prejuízo destas.

Departamento de História

Pontifícia Universidade Católica

Porto Alegre, Brasil 


\section{NOTAS}

${ }^{1}$ H.C. Allen, História dos Estados Unidos da América (Rio de Janeiro: Forense, 1964), p. 113, comentando a mensagem do Presidente Monroe, datada de 2 de dezembro de 1823, diz "possuir a mesma uma passagem de grande importância para o desenvolvimento da política estrangeira dos E.U.A." e cita: "[...] é própria para afirmar, como princípio em que estão envolvidos direitos e interesses dos Estados Unidos, que os continentes americanos, pela livre e independente situação que conquistaram e mantêm, não deverão ser, de agora em diante, considerados centros de colonização futura de qualquer potência européia..."

${ }^{2}$ A A mazônia e a cobiça internacional, 3. ed. (Rio de Janciro: Record, 1968), p. 63.

3 Id., ibidem, p. 63-4.

${ }^{4}$ Moniz Bandeira, Presença dos Estados Unidos no Brasil (Rio de Janeiro: Civilização Brasileira, 1973), p. 87, refere a existência de ofício de José Silvestre Rebelo a Miguel Calmon du Pin e Almeida, datado de 22/2/1831, Rio de Janeiro.

${ }^{5}$ Arthur Cezar Ferreira Reis, op. cit., p. 64.

6 "The Commercial Prospects of the South" in Nicia Vilela Luz, A Amazônia para os negros americanos (Rio de Janeiro: Saga, 1968), pp. 58-9.

${ }^{7}$ Moniz Bandeira, op. cit., p. 88.

${ }^{8}$ H.C. Allen, Op. cit., p. 115.

9 Moniz Bandeira, op. cit., p. 86.

10 Apud Moniz Bandeira, op. cit., p. 88.

11 Antônio Rocha Almeida, História do Brasil (Porto Alegre: Ética Impressora, 1969), v. I, p. 202, assim se reporta: "Pelo decreto imperial n. 1037 , de 30 de agosto de 1852 foi concedida a Irineu Evangelista de Souza permissão para explorar a navegação do rio Amazonas, seus afluentes e confluentes."

12 Moniz Bardeira, op. cit., p. 90.

13 Id., ibidem, p. 119.

${ }^{14}$ Frank Goldmann, "Aspectos das migrações norte-americanas após a guerra civil" in Sérgio Buarque de Holanda (org.), História geral da civilização brasileira (São Paulo: Difusão Européia do Livro, 1969), v. V, t. II, pp. 262-4.

15 Donald Marquand Dozer, América Latina (Porto Alegre: Globo, 1966), p. 370.

16 Moniz Bandeira, op. cit., p. 124.

17 Vianna Moog, Bandeirantes e Pioneiros, $11^{\mathrm{a}}$ ed. (Porto Alegre: Globo, 1974), pp. 34-5.

18

Os autores são unânimes em 'referenciar o papel de "pólo de atração" que a cidade exerceu sobre os imigrados. Muitos deles não conseguindo êxito em suas profissões de origem, seguiram pela Vila Americana, que, progredindo como cidade, guardou no seu passado histórico as marcas de uma cultura nitidamente norte-americana.

19

(São Paulo: Buarque de Holanda, in Prefácio a Memórias de um colono no Brasil,de Thomas Davatz

${ }^{20}$ Frank Goldmann, op. cit., p. 273. 
21 Antonia F. de Almeida Wright, "Brasil - Estados Unidos, 1831-1889" in Sérgio Buarque d Holanda (org.), História geral da civilização brasileira (São Paulo: Difusão Européia do Livro, 1969 v. VI, t. II, p. 201, refere: “O sucesso, o progresso técnico e a pujança da nação americana revelada especialmente durante o período conhecido como o da 'Reconstrução' após a guerra de Secessão, eram fatos que por si só refletiam aquela imagem favorável que diplomatas às vezes comprometiam, mas nâ destruíam. Nem mesmo o Imperador Pedro II resistiu à tentação de ver de perto a exposição desse progresso. Viajou para os Estados Unidos em visita à Exposição do Centenário em 1876, pagando o seu ingresso como outro visitante qualquer." 